\title{
Towards New Standards of Competence for Hydrographers and Nautical Cartographers
}

Andrew Armstrong, United States of America

National Oceanic and Atmospheric Administration-University of New Hampshire Joint Hydrographic Center

Ron Furness, Australia

IIC Technologies Ltd

Gordon Johnston, United Kingdom

Venture Geomatics Limited

Nicolas Seube, France

École Nationale Supérieure de Techniques Avancées Bretagne

Lysandros Tsoulos, Greece

National Technical University Athens

Topic: The Hydrographic Profession

\section{ABSTRACT}

Expectations and demands for education and training and the achievement and maintenance of core and new competencies in the hydrographic community are changing apace. The accepted international minimum competency standards for hydrographic surveyors and nautical cartographers have served the profession well, but are presently under review against these changed expectations. Community participation will be critical as the standards deal with and address the changes, ever mindful of the need for effective delivery of education and training across the wider profession.

\section{INTRODUCTION}

The FIG/IHO/ICA International Board for Standards of Competence (IBSC) for Hydrographic Surveyors and Nautical Cartographers (hereafter referred as "the Board") have guided the delivery of education and training for Hydrographers and nautical cartographers since it was formed in 1977.

The Standards, as promulgated in IHO Publications S-5 [IHO, 2011] and S-8 [IHO, 2010] (formerly M-5 and M-8), recognize two levels of hydrographic (or cartographic) competence-Category $A$ and Category B. The current Editions of S-5 and S-8 can be downloaded from the IHO website. Category A programmes offer a comprehensive and broad-based knowledge in all aspects of the theory and practice of hydrography or nautical cartography. Category B programmes provide the practical comprehension, along with the essential theoretical background, necessary for individuals to carry out the various hydrographic survey or nautical cartographic tasks.

The standards have been structured so that Category B programs provide technical education to support a set of fundamental and practical competencies. Category A educational programs must include all the Category $B$ competencies plus additional detailed-level competencies. This means that Category B is a subset of Category A, and the S-5 S-8 standards are structured accordingly. Along with hydrographic and cartographic technology, the personnel and training needs of Hydrographic Offices and the hydrographic industry have evolved considerably since 1977.

\section{THE BOARD, THE STANDARDS AND THE RECOGNITION PROCESS}

The Board comprises ten Members representing the three constituent organizations: FIG, the International Federation of Surveyors (4); IHO, the International Hydrographic Organization (4); and ICA, the International Cartographic Association (2). The Board Secretariat is provided from the IHO. The present Board comprises a cross section of experts representing the broader hydrographic 
community and are from Australia, France, Germany, Greece, India, Malaysia, New Zealand, Trinidad and Tobago, United Kingdom and the United States. The Secretary brings his experience from Brazil. The Board meets annually and it is charged with maintaining S-5 and S-8 standards and considering course curricula submissions against these standards for recognition. Recognition of courses is granted only when those curricula meet the appropriate requirements. A list of those courses recognised is available online [IHO, 2010(2)].

The Board's operations are governed by its published Terms of Reference and Rules of Procedure [IHO, 2011(2)] as ratified by the constituent organizations. The decisions made by the Board are independent. A small submission fee and annual fee are levied on submitting organizations, which assists in funding the Board's activities although Members largely fund their own participation.

The Board has recognised various pressures for change that will be revisited below and is in the process of reviewing both standards in order to modernise them and better reflect modern requirements for achieving qualified hydrographic surveyors and nautical cartographers at various levels of competence.

Courses seeking recognition are submitted by competent educational and formal training bodies by 31 December each year. The Board meets subsequently after each member has reviewed submissions and in plenary the Board considers each submission. Once recognised, course recognition remains valid for six (6) years assuming its delivery continues. After six years a new submission is required.

The Board does not recognise individuals but has introduced minimum requirements by which it will recognise national or regional schemes, which in turn recognise or accredit individuals. Such schemes typically require qualified persons to remain current through access to continuing professional programs.

The Board will begin the process of changing the Standards with S-5. The S- 5 Standards indicate the minimum degree of knowledge and experience considered necessary for hydrographic surveyors, and provide a set of programme outlines against which the Board may evaluate programmes submitted for recognition.

Early editions of M-5 were significantly changed with the publication of the fifth edition, which represented a fundamental change of approach in order to make the Standards more applicable to the different requirements for hydrographic surveyors in government and industry. The fifth edition Standards provided basic and essential subjects that are required for all hydrographic surveyors and a choice of three options for specialization in Nautical Charting Surveys, Surveys for Coastal Zone Management or Industrial Offshore Surveys.

The sixth edition incorporated a change in format, to facilitate easier cross-referencing between syllabus topics and programmes which were submitted for recognition and also included minor changes in content to eliminate duplication of subject matter and to reflect the evolution of technology. The seventh edition eliminated the distinction between Full/Academic recognition and increased the emphasis on developing techniques of GPS, multibeam sonar systems and ECDIS. The eighth edition eliminated the Specialisms and re-structured the Syllabus in two different parts: the "Minimum Standards", including Basic and Essential Subjects and the "Optional Units".

The ninth edition (2001) provided a better definition of the three levels of knowledge (Fundamental, Practical, Detailed) identified in the syllabus. Nautical Science was moved to the Basic Subjects, and was modified to reflect the minimum knowledge required by an hydrographic surveyor. This edition contained a more detailed description of each subject, which were divided into Category A / Category $B$ and Category A-only learning objectives.

The tenth edition makes changes to Section 3 "Submission of Courses", introduces a new Appendix V "Annual Assessment Report" and also reflects the change of the Board's name which became "FIG/IHO/ICA International Board on Standards of Competence for Hydrographic Surveyors and Nautical Cartographers" as agreed during the 31st Meeting. 
In 2009 the IHO restructured its publications and the M-5 Standard was renamed S-5. The eleventh edition includes a new and expanded section relating to the recognition of Schemes that certify the competency of Individuals beyond their formal education and training.

The present Standard S-5 comprises:

- Educational and training programs at two levels:

$$
\text { - Category A }
$$

- Category B

- 3 Knowledge Levels: Fundamental, Practical \& Detailed

- 2 Groups of Subjects: Basic \& Essential

- 7 options (Nautical charting, Hydrography to Support Port Management and Coastal Engineering, Offshore Seismic Surveys, Offshore Construction Hydrography, Remote sensing, Military Hydrography, Inland Waters Hydrography)

- Individual Recognition Schemes

Category B is currently defined as a programme that provides a practical comprehension of hydrographic surveying for individuals - along with the essential theoretical background - with the skill to carry out the various Hydrographic surveying tasks.

- Example competency: "Explain the principles of various types of water level gauges and poles. Describe characteristics of river, coastal and offshore water level gauges. Install and operate water level gauges and poles".

Category $\mathrm{A}$ is a programme which provides a comprehensive and broad-based knowledge in all aspects of the theory and practice of hydrography and allied disciplines for individuals who will practice analytical reasoning, decision making and development of solutions to non-routine problems.

- Example Competency: "Evaluate and select appropriate instruments and sites for water level monitoring. Calibrate analogue and digital recording water level gauges. Evaluate sources of error. Apply appropriate corrections".

Individual recognition schemes are regional or national bodies that evaluate, certify, and track the competence of individual hydrographers. S- 5 sets out standards of organization and content for these schemes. Recognized schemes may certify individuals at levels other than Category A, or B, but only individuals who have completed a Category A or B course may be certified as Category A or B Hydrographers. At the May 2012, $35^{\text {th }}$ meeting of the Board in Buenos Aires, Argentina, the Board recognized the Australasian Hydrographic Surveyors Certification Panel (AHSCP) as the first approved scheme of individual hydrographers competence.

\section{NEW CHALLENGES IN HYDROGRAPHY EDUCATION AND TRAINING}

It has become evident to the Board that there are a number of influencing factors that bring about imperatives for change in the way hydrographic surveyors and nautical cartographers are educated to meet modern hydrographic practice and products requirements.

New use of the seas has shifted the hydrographic products from those intended mainly for navigation safety to a wide variety of deliverables, motivated by emergent fields like energy production (wind farms, marine turbines, etc.), marine environment understanding and protection (habitat mapping, coastal erosion monitoring, coral reef mapping, etc.), remote sensing bathymetry (using bathymetric LiDAR, AUVs, ASVs, or satellite data). Field operations are and will be conducted in the near future at a wide variety of scales: from detailed port infrastructure inspection survey to regional satellite bathymetry.

To respond to these new challenges, equipment and software are becoming more and more sophisticated and automated. We are now dealing with hydrographic systems (being by essence kinematic mapping systems), composed of complex sensors incorporating a high level of technology and embedded software. 
The increasing complexity of field operations with added requirements for skills such as project management, financial acuity and broader professional aptitude with greater cross discipline experience and exposure - in some cases without actual seamanship skills (LiDAR operations perhaps or port based operations) requires consideration and definition.

The increasing amount of data that are collected need to be processed (cleaned, controlled, generalised), and integrated in marine geospatial data management systems. Data processing and management systems incorporate advanced numerical methods enabling the hydrographer access to high-level models built from multi-sensors raw datasets. These stretch the knowledge required by hydrographers.

Technology in the field increasingly requires better qualified technicians and operators who may not be required to go further than a consolidated Category B programme. This apparent conflict is compounded by the increase in demand for competent hydrographers. More and more there is little time available as busy individuals attempt to balance their work and leisure life. The challenge in its broader sense is to be able to provide adequate technical foundations combined with appropriate practical exercises but without removing the individual from their work environment for too long a period or requiring the educational organisation to invest in complex and expensive equipment that may only be used a few weeks per year.

The influence of blended, direct and distance learning initiatives is beginning to have an impact. The growing perception now is that modular, short educational courses coupled with intensive time on practical and field work may offer a solution that combines the desires of individual and course providers through a flexible approach to the selection, completion and assessment of course elements making up. For the Board these must be of adequate time and rigour as well as accumulating into a comprehensive cover of any minimum Standards.

In the framework of these new challenges the Board has decided to strengthen the importance of programme review as a process for evaluating and continuously enhancing the quality and currency of programmes. The evaluation will be conducted through a combination of self-assessment, followed by peer on-site consultation by members of the Board, for the mutual benefit of all parties. In addition, a visit will serve to raise the profile of hydrography and nautical cartography nationally and regionally.

\section{TOWARDS NEW STANDARDS}

Early thoughts of the Board suggest the separation of the present Category B and Category A requirements and a future separate path of development for each. In view of the foreseen challenges in hydrography and nautical cartography, the Board believes that a fundamental change to the structure of the Standards is appropriate. The Board is in the process of developing a new structure for S-5 and S-8 that will separate the Standards for Category A and Category B programs. Standards for each category will be designed and developed independently.

Category B standards will be aimed at the basic educational and training requirements for hydrographic technicians and field hydrographers (S-5), and nautical cartographers (S-8). Category A standards will be aimed at the theoretical educational and foundational background necessary for Hydrographers/Nautical Cartographers-In-Charge and hydrographic/cartographic managers who will develop specifications for surveys and charts, establish quality control and quality assurance systems, and respond to the specific requirements of a full range of hydrographic/cartographic projects.

For both Category A and Category B standards, the ability to conduct or operate hydrographic surveys in the field or utilize hydrographic/cartographic databases to compile and produce charts, remains an essential competence, and thus an essential part of education and training through the necessity of practicals (field exercises/projects).

The Board expects to complete new S-5 standards by 2014, and intends to communicate about this process before the final release of the new S-5 and S-8. 


\section{THE DEVELOPMENT PATH}

The Board will need to grapple with various and varying impacts as it works through how best it can provide guidance for minimum standards into the future. Anecdotally, at least, it is clear to the Board that the demand for qualified hydrographic surveyors and nautical cartographers is increasing. Simultaneously, as evidenced partly by the creation and introduction of professional bodies that review, certify and track the competences of practitioners within the industry, there is an increasing clamour for qualified competent hydrographic/cartographic personnel. Many hydrographic contracts, by way of example, now demand evidence of formal and appropriate hydrographic/cartographic qualification and competence as a consideration in the evaluation of tender responses. Naturally, this is accompanied by demand from the personnel themselves for opportunities to study and to continue their skill refreshment within accredited and recognised programs that provide evidenced continuation of individual, and thus consequently, corporate, professional competency.

Those personnel entering the profession do not find it easy in at least some parts of the world to find courses that suit their needs. Not everyone seeks a military career that was hitherto often the genesis of many a longer term successful hydrographic career. The Australasian region, for example, has struggled to sustain its civilian hydrographic training courses and even recognised courses have foundered for a number of reasons. A new attempt to provide such initial training opportunities is presently under way.

The reasons for the difficulty of maintaining courses are varied, but for those bodies offering them, it all boils down to the critical number of students applying for the course - or rather - a lack of sufficient numbers to sustain such specialist and high cost training and education. Factors affecting student numbers include costs, time, and changing expectations on the parts of both students and employers. These are high on the lists of influencing factors for those who make their difficulties known.

Industry-wide, and broadly speaking, the employment of hydrographic professionals is changing from life-time careers to project and contract employment which frequently requires skill-set refreshment and new technology-based competencies which sometimes are found to be lagging in established courses. Longer term practitioners require access to change learning paradigms. Students bring changed expectations therefore, given that they must work in such an industrial environment. Expectations are high among modern students: they are typically computer literate and modern survey equipment competent, but require rapid and often short term results for a specific instance of employment.

Employers, on the other hand, have complementary expectations that they will either find such students in the market place or will take on board their own training in order to meet the exigencies of the tenderer's expectations and project demands. Demand for immediately functional skill sets is high. Increasingly, the market place cannot immediately deliver.

The educational world itself is in turn influenced by changing technological and methodological imperatives. The older forms of institution of university or national agency are being challenged to deliver. Connectivity and the introduction of so-called e-learning methods, blended learning techniques, webinars, e-seminars, e-meetings and the like, have naturally attracted the attention of hydrographic agencies and companies and their staff and it is not surprising that, given the offshore nature of much of the industry, attempts are being made to harness the better technologies and methods to achieve the requirements outlined above. The potential of these forms of program delivery are beguiling and seemingly cost-effective in their promises however their successful delivery largely still needs to be proven.

All components of the hydrographic profession face challenges as to how best to ensure the continuance of the high standards and how best to ensure the continuation of best practices based on minimum standards of competence world-wide. A cooperative approach will best deliver future guidance to all. 


\section{CONCLUSIONS}

Attitudes toward training and education are changing. The hydrographic profession is not immune from such broader pressures. There are, however, some unique aspects of hydrographic surveying that impact on how training and education can best be delivered. While the S-5 approach has stood the profession in good stead and is generally well recognised throughout the hydrographic world, there is sufficient evidence to suggest it needs a complete review and overhaul to bring it in line with current expectations of how to achieve community-wide best practice for minimum standards of competence. The Board, in facing the challenges outlined above, anticipates posting its draft revisions online for stake-holder feedback and contribution. This paper itself is to be considered a part of this process.

\section{REFERENCES}

IHO-International Hydrographic Organization. 2011. "Standards of Competence for Hydrographic Surveyors," Publication S-5, 11 ${ }^{\text {th }}$ Edition, Version 11.0.1-May 2011, accessed 24 June 2012. http://www.iho.int/iho_pubs/standard/S-5_Ed_11.0.1_06May2011_Standards-Hydro.pdf

IHO-International Hydrographic Organization. 2010. "Standards of Competence for Nautical Cartographers," Publication S-8, 3rd Edition, 2010, accessed 24 June 2012.

http://www.iho.int/iho_pubs/standard/S_8_3rd_Jan_2011.pdf

IHO-International Hydrographic Organization. 2010(2). "List of Recognized Courses Hydrography," May 2010, accessed 24 June 2012.

http://www.iho.int/mtg_docs/com_wg/AB/AB33/LISTMAY10.pdf

IHO-International Hydrographic Organization. 2011(2). FIG/IHO/ICA International Board (IB) on Standards of Competence, "Terms of Reference," Revision 1, 2011 , accessed 24 June 2012. http://www.iho.int/mtg_docs/com_wg/TOR/IBSC_TorsRops_2011-rev1.pdf

\section{BIOGRAPHIES}

The authors have a wide variety of hydrographic and cartographic experience in government, academia, and private industry. All are members of the FIG/IHO/ICA International Board on Standards of Competence for Hydrographic Surveyors and Nautical Cartographers 